\title{
Optimized Bandwidth Enhanced Wideband Microstrip Antenna for 5G Applications
}

\author{
Navneet Singh, Amit Jain, Dinesh Kumar Singh
}

\begin{abstract}
In this article, a single port with truncated corner and common T-shaped notch loaded microstrip patch antenna for bandwidth enhancement is presented which is useable for mid band of $5 G$ applications. The design of this prototyped antenna is obtained by loading truncated corner and T-shaped notch on rectangular patch antenna having $50 \Omega$ microstrip line feed. The optimized antenna 5 is selected as proposed antenna at design frequency $3 \mathrm{GHz}$ among antenna 1- antenna 5after study of simulated results through IE3D Mentor Graphics simulation software. Proposed antenna covers a wide bandwidth from 2.39 to $4.04 \mathrm{GHz}$ and fractional bandwidth of $51.3 \%$ with pair of resonance frequency having return loss of $-23.38 \mathrm{~dB}$ and -29.65 dB respectively.
\end{abstract}

Keywords: Truncated corner; Notch; Bandwidth; Resonance frequency; Return loss.

\section{INTRODUCTION}

$\mathrm{D}$ ue to advantages of light weight, low profile, simple structure and easy fabrication, so many investigations have been performed on the traditional microstrip patch antennas. There are so many design methods have been performed and developed for the enhancement of the bandwidth of these antennas. Based on above attractive features, microstrip antenna is a good candidate for fifth generation (5G) mobile communication system.

$5 \mathrm{G}$ can be implemented in three bands like low-band (600-850 MHz), mid-band (2.3-4.7 GHz) and high band millimeter wave $(24-40 \mathrm{GHz})$.

The bands ranging from $3 \mathrm{GHz}$ to $5 \mathrm{GHz}$ have been promoted in many countries for $5 \mathrm{G}$ services such as 3.1- 3.55 $\mathrm{GHz}$ and $3.7-3.8 \mathrm{GHz}$ in USA, 3.3-3.6 GHz in India and 3.4-3.8 GHz in Europe [1].

Several studies have been performed on the development of low-profile and broad band microstrip antenna. The impedance bandwidth of antenna structure can also be improved by loading the slots.

Using elliptical slot and placing inverted T-shaped stub with three reverse U-shape stubs, different parameters of proposed antenna has been observed also have better return

Manuscript received on January 10, 2021.

Revised Manuscript received on January 20, 2021.

Manuscript published on January 30, 2021.

* Correspondence Author

Navneet Singh*, Research Scholar, School of Engineering \& Technology, Shri Venkateshwara University, Gajraula, (UP), India. Email: navneetsvu@gmail.com

Dr. Amit Jain, School of Engineering \& Technology, Shri Venkateshwara University, Gajraula, (UP), India. Email: rinku.j19@gmail.com

Dr. Dinesh Kumar Singh, Department of IT, DSMNR University, Lucknow, (UP), India. Email: dineshsingh025@gmail.com

(C) The Authors. Published by Blue Eyes Intelligence Engineering and Sciences Publication (BEIESP). This is an open access article under the CC BY-NC-ND license (http://creativecommons.org/licenses/by-nc-nd/4.0/) loss with compact size [2]. The impedance bandwidth of radiating patch enhanced by loaded with slots and different shapes of fractal boundary [3]. By placing the slot which may be of different shapes like inverted U-shape, L-shape addition with rectangular ring strip as well as defected ground plane, a multiband antenna has been studied and designed [4],[5].

By loading the slot of $\mathrm{H}$ and $\mathrm{U}$ - shaped bandwidth of $14 \%$ and $30 \%$ have been observed respectively in microstrip patch antenna [6],[7].

Although with the help of stub loading and E-shaped loading in patch antenna, a better impedance bandwidth of approx. $40 \%$ has been achieved [8],[9]. Irrespective to the rectangular and square patch, a triangular patch antenna also shows the enhanced bandwidth by loading the notch and slot [10].

In this article, a broadband and low-profile patch antenna is designed and discussed for the $5 \mathrm{G}$ wireless communication system. Truncated corner and multi-notched structure are designed to shift the resonance frequency and enhance the impedance bandwidth. The prototype design of antenna has been simulated with Mentor Graphics IE3D software.

\section{EXPLANATION OF THE PROPOSED STRUCTURE}

The final optimized geometry of proposed antenna is illustrated in Figure1, which is implemented on FR4 dielectric material having constant 4.4, thickness of $1.6 \mathrm{~mm}$ and loss tangent of $0.01[11]$.

For a design frequency of $3 \mathrm{GHz}$, the calculated area of rectangular patch is $23.4 \times 30.4 \mathrm{~mm} 2$. For impedance matching, $50 \Omega$ microstrip line feed is used having area $5 \times 3$ $\mathrm{mm} 2$. The design specifications of proposed antenna geometry are given in Table 1.

Table1: Design Specifications of Proposed Antenna Geometry

\begin{tabular}{|c|c|c|}
\hline S. No. & Parameters & Value (mm) \\
\hline 1. & A & 33.4 \\
\hline 2. & B & 54.4 \\
\hline 3. & C & 23.4 \\
\hline 4. & D & 30.4 \\
\hline 5. & a & 5 \\
\hline 6. & b & 3 \\
\hline 7. & c & 5 \\
\hline 8. & d & 2 \\
\hline
\end{tabular}




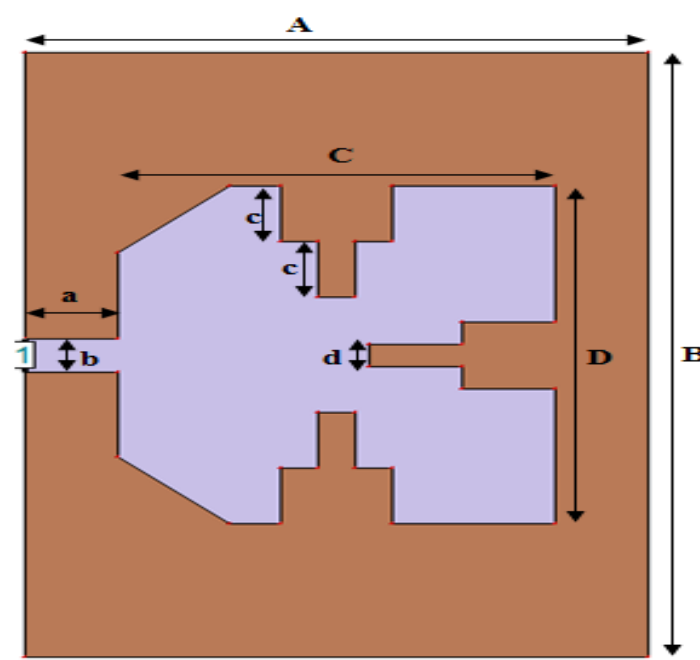

Figure 1: Final Optimized Geometry of Proposed Antenna

\section{CONVERSATION OF DESIGN STEPS AND SIMULATION RESULTS}

For the designing the structure of proposed antenna, the initial basic area of the rectangular patch is $23.4 \times 30.4 \mathrm{~mm}^{2}$ and the ground plane area is $33.4 \times 40.4 \mathrm{~mm}^{2}$. In simulation process, a single port $50 \Omega$ microstrip line feed has been used with area $5 \times 3 \mathrm{~mm}^{2}$ for impedance matching. The initial structure and the simulated return loss graph of the basic patch antenna is shown in Figure. 2. From the Figure 2 (b) it is observed that graph has two frequency band having bandwidth $16.96 \%$ in range from

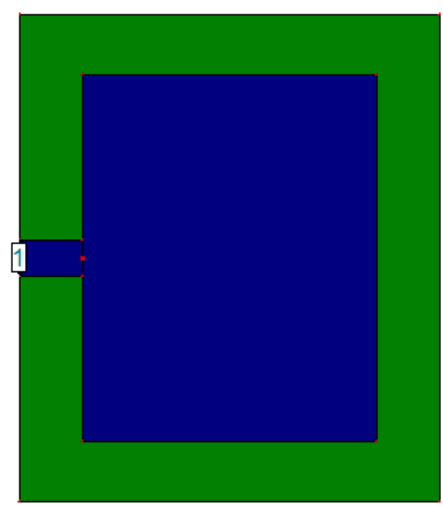

(a)

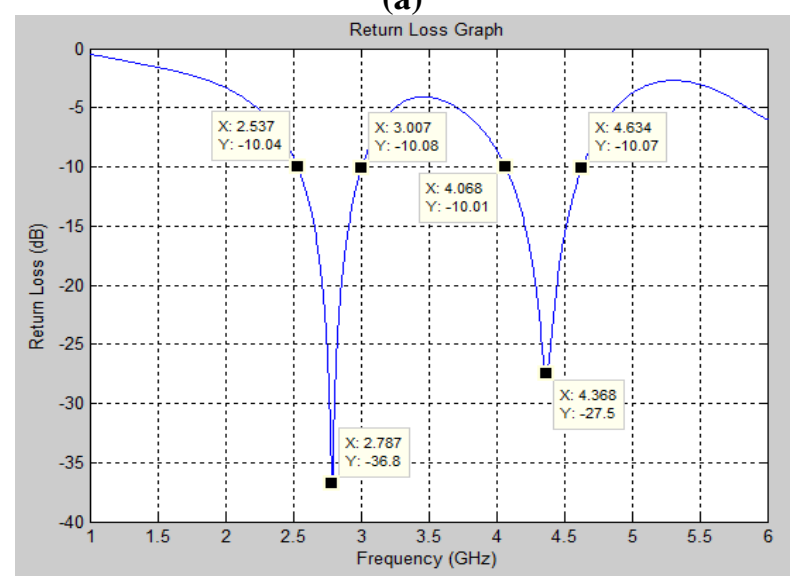

(b)

Figure 2: (a) Basic Structure of Patch antenna (b) Return Loss Graph of Basic Structure of Patch Antenna

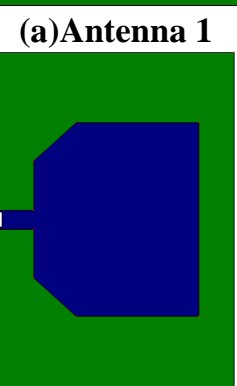

(b)Antenna 2
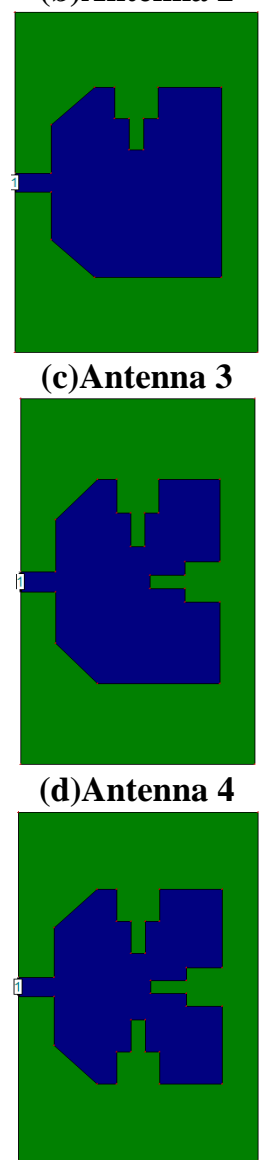

(e)Antenna 5

Figure.3: Design Steps for Optimized Proposed Antenna

2.537 $\mathrm{GHz}$ to $3.007 \mathrm{GHz}$ and $13 \%$ in range from $4.068 \mathrm{GHz}$ to $4.634 \mathrm{GHz}$ respectively. The resonance frequencies of these bands are $2.787 \mathrm{GHz}$ and $4.368 \mathrm{GHz}$ with return loss of $-36.8 \mathrm{~dB}$ and $-27.5 \mathrm{~dB}$ respectively.

For getting the enhanced bandwidth, the different design steps of optimized proposed antenna (from antenna1 to proposed antenna) having truncated corner and T-shaped notch is shown in Figure 3. 


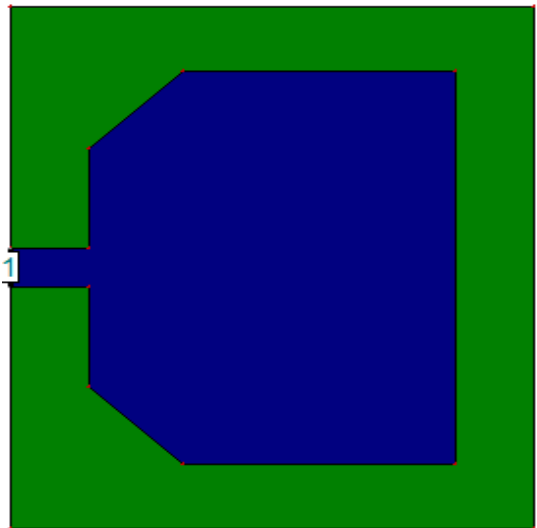

(a)

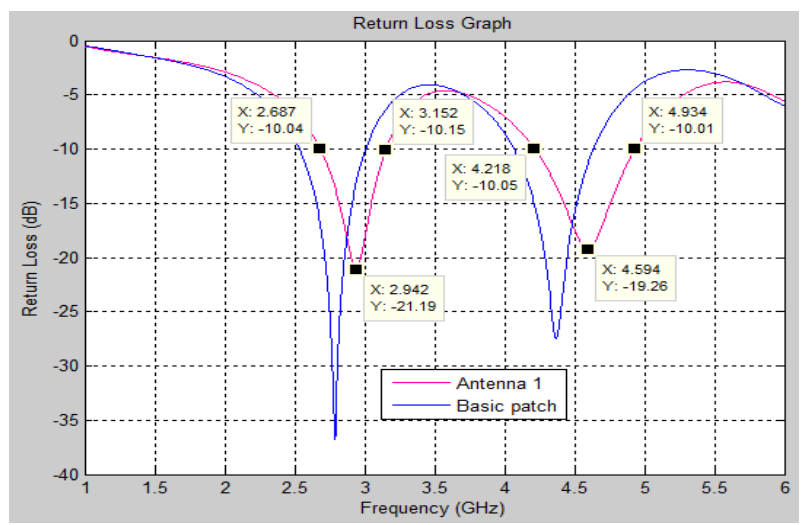

(b)

Figure. 4: (a) Design of Antenna 1 (b) Return Loss Graph of Antenna 1

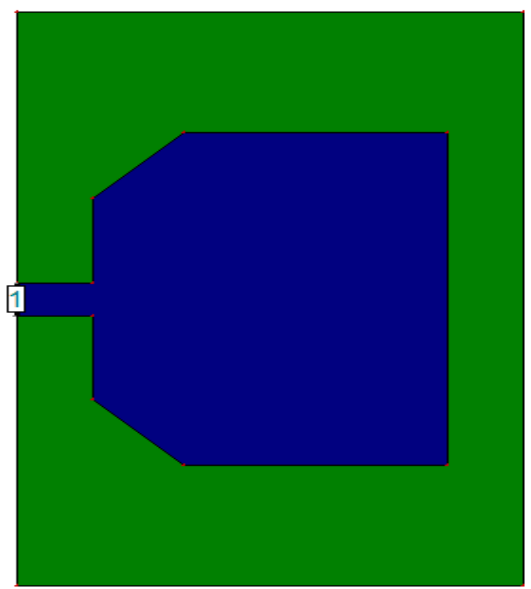

(a)

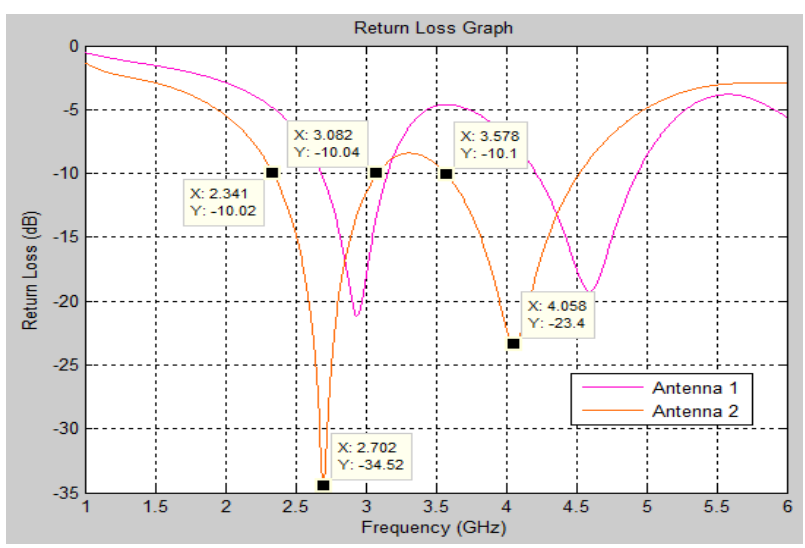

(b)

Figure. 5: (a) Design of Antenna 2 (b) Return Loss Graph of Antenna 2
For getting the design of the proposed antenna, the first step is shown in Figure. 4(a) as antenna 1. For this design there is truncating the corners of the basic patch from the side of the radiating patch edge. The dimensions of both the truncated corners are same having $6 \mathrm{~mm}$ across length side and $6 \mathrm{~mm}$ across width side of radiating patch edge. Doing this process the simulated return loss graph is shown in Figure 4(b).From figure it is observed that the frequency band graph is shifted towards the higher band side in comparison to basic patch frequency band graph with dual frequency band having bandwidth $15.93 \%$ in range from $2.687 \mathrm{GHz}$ to $3.152 \mathrm{GHz}$ and $15.65 \%$ in range from $4.218 \mathrm{GHz}$ to $4.934 \mathrm{GHz}$ respectively. The resonance frequencies of these bands are $2.942 \mathrm{GHz}$ and $4.594 \mathrm{GHz}$ with return loss of $-21.19 \mathrm{~dB}$ and $-19.26 \mathrm{~dB}$ respectively. For getting the design of the proposed antenna, the second step is shown in Figure.5 (a) as antenna 2. For this design the width of the ground has been increased. The simulated return loss graph for this design is shown in Figure 5 (b). From figure it has been observed that the frequency band graph is shifted towards the lower band side in comparison to antenna 1 frequency band graph with dual frequency band having bandwidth $27.33 \%$ in range from $2.341 \mathrm{GHz}$ to $3.082 \mathrm{GHz}$ and $23.32 \%$ in range from 3.578 $\mathrm{GHz}$ to $4.519 \mathrm{GHz}$ respectively. The resonance frequencies of these bands are $2.702 \mathrm{GHz}$ and $4.058 \mathrm{GHz}$ with return loss of $-34.52 \mathrm{~dB}$ and -23.4 respectively.

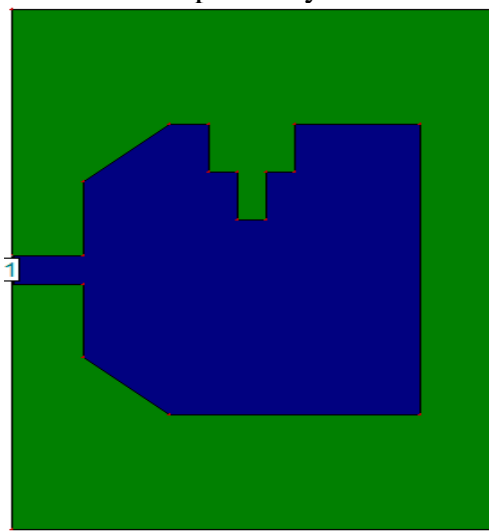

(a)

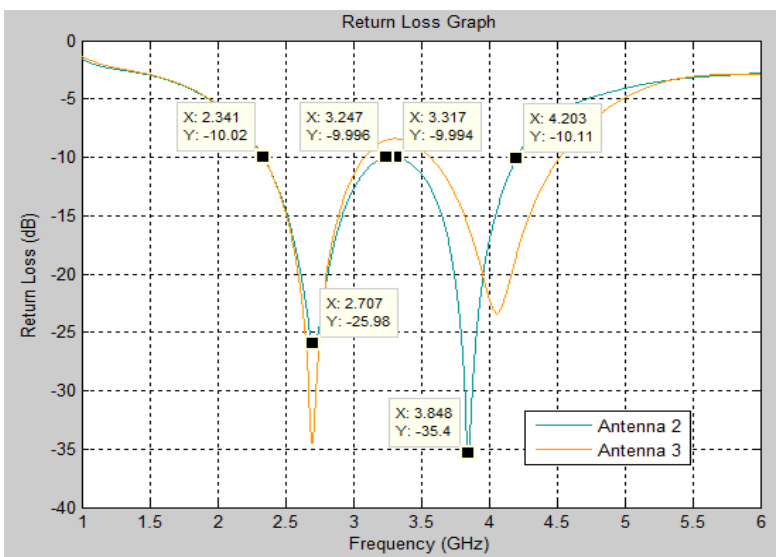

(b)

Figure. 6: (a) Design of Antenna 3 (b) Return Loss Graph of Antenna 3

Published By:

Blue Eyes Intelligence Engineering and Sciences Publication (BEIESP) (C) Copyright: All rights reserved.

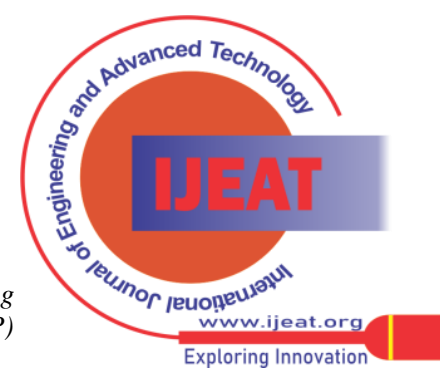




\section{Optimized Bandwidth Enhanced Wideband Microstrip Antenna for 5G Applications}

The third step for getting the design of the proposed antenna is shown in Figure. 6 (a) as antenna 3. For this design a T-shaped notch has been loaded at the center of the upper side length of the patch up to $10 \mathrm{~mm}$. The simulated return loss graph for this design is shown in Figure 6 (b). From figure it has been observed that the left side portion of the frequency band graph is remains same but the right portion of the shifted towards the lower band side in comparison to antenna 2 frequency band graph with dual frequency band having bandwidth $32.43 \%$ in range from $2.341 \mathrm{GHz}$ to 3.247 $\mathrm{GHz}$ and $23.56 \%$ in range from $3.317 \mathrm{GHz}$ to $4.203 \mathrm{GHz}$ respectively. The resonance frequencies of these bands are $2.707 \mathrm{GHz}$ and $3.848 \mathrm{GHz}$ with return loss of $-25.98 \mathrm{~dB}$ and -35.4 respectively.

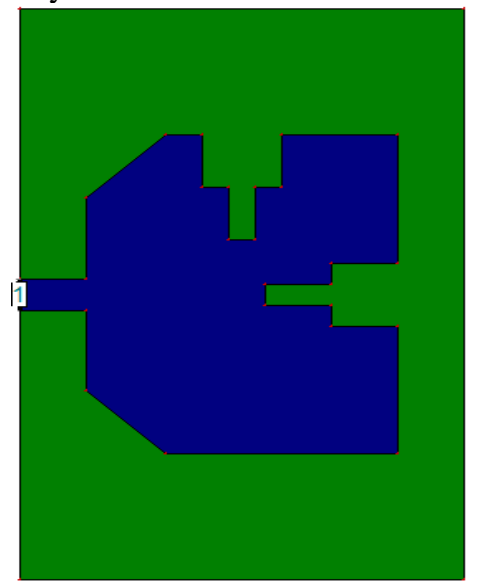

(a)

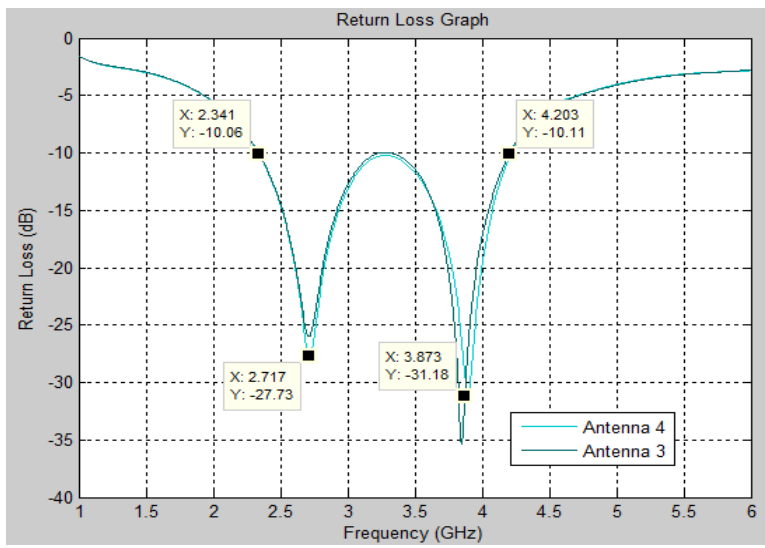

(b)

Figure. 7: (a) Design of Antenna 4 (b) Return Loss Graph of Antenna 4

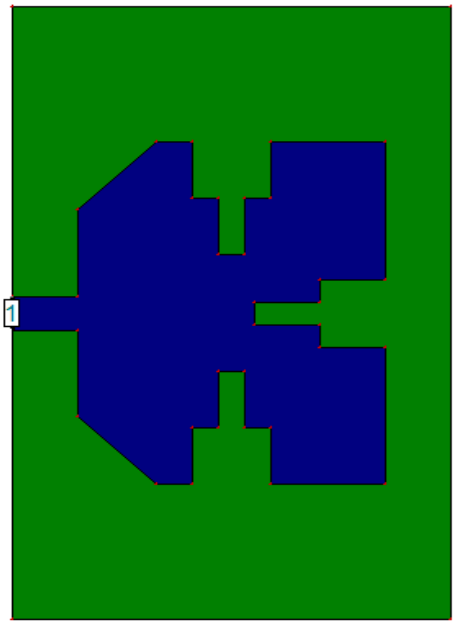

(a)

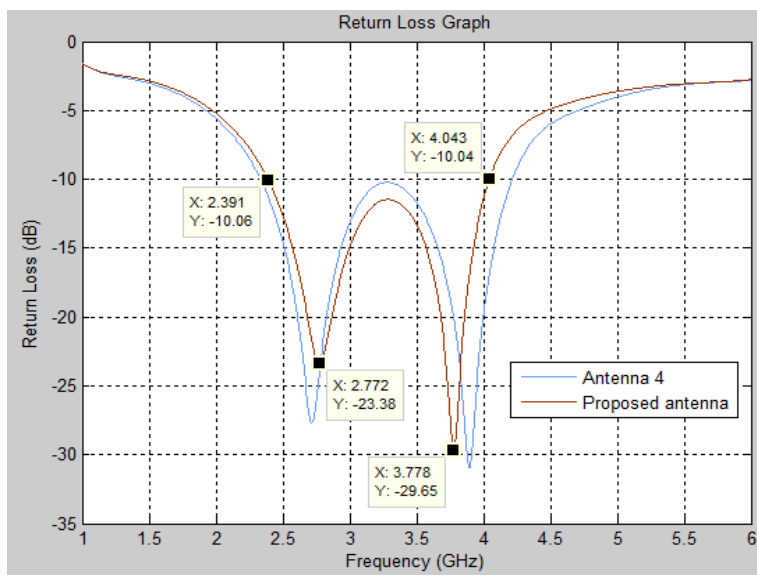

(b)

Figure. 8: (a) Design of Proposed Antenna (b) Return Loss Graph of Proposed Antenna

Figure 7 (a) shows the fourth step for getting the design of the proposed antenna as antenna 4 . For this design and another T-shaped notch has been loaded at the center of the right-side width of the patch up to $10 \mathrm{~mm}$. The simulated return loss graph for this design is shown in Figure 7 (b). From figure it has been observed that graph have single wideband having the bandwidth $56.9 \%$ in range from 2.341 to $4.203 \mathrm{GHz}$ with two resonance peaks. The resonance frequencies of this band are $2.717 \mathrm{GHz}$ and $3.873 \mathrm{GHz}$ with return loss of $-27.73 \mathrm{~dB}$ and -31.18 respectively. From figure it is also observed that the lobe of the band is just nearer to the $-10 \mathrm{db}$ line that may create this single broad band to the two bands while taking measurement of the hardware of this design.

For care of above problem another T- shaped notch having the same area as other two notches, is loaded to center of the bottom side of length of the patch. This is the final step for design of the proposed antenna which is shown in Figure 8 (a). The simulated return loss graph is shown in Figure 8 (b) from where is it has been observed that graph has single wideband having impedance bandwidth for $S_{11}$ less $-10 \mathrm{~dB}$ is from $2.391 \mathrm{GHz}$ to 4.043 with the relative bandwidth of 51.3 $\%$ as well as two resonance peaks. The resonance frequency of this band is $2.772 \mathrm{GHz}$ and 3.778 having return loss of -23.38 and -29.65 respectively.

\section{CONCLUSION}

A truncated corner and T-shaped notch loaded low-profile and widebend rectangular microstrip patch antenna with $50 \Omega$ microstrip feed has been designed and simulated for $5 \mathrm{G}$ applications. This antenna has been designed from rectangular patch by means of two truncated corner and three T-shaped notch having same area for getting improved bandwidth. The proposed design has enhanced bandwidth of $51.3 \%(2.391 \mathrm{GHz}-4.043 \mathrm{GHz})$ with return loss of $-23.38 \mathrm{~dB}$ and $-29.65 \mathrm{~dB}$ at resonance frequencies $2.772 \mathrm{GHz}$ and 3.778 $\mathrm{GHz}$ respectively which is a remarkable result covering frequency bands between $3 \mathrm{GHz}$ and $5 \mathrm{GHz}$ which is required for mid band of the $5 \mathrm{G}$ frequency band. With the above favorable outcomes, the proposed antenna can be useful for the 5G wireless communication systems.

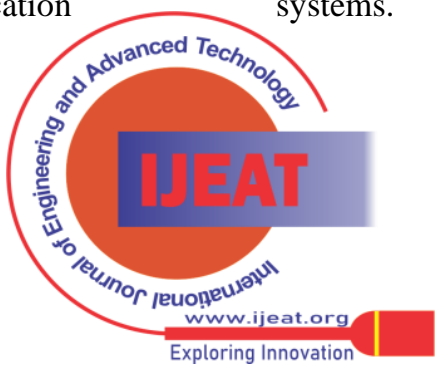




\section{REFERENCES}

1. An, Wenxing \& Li, Yue \& Fu, Haipeng \& Ma, Jianguo \& Chen, Weigang \& Feng, Botao. (2018). Low-Profile and Wideband Microstrip Antenna with Stable Gain for 5G Wireless Applications. IEEE Antennas and Wireless Propagation Letters. PP. 1-1. 10.1109/LAWP.2018.2806369.

2. K. P. Kumar, B. Amulya and B. V. Rao, "Compact Multiband Printed Antenna Design and Analysis", International Journal of Control and Automation, vol. 13, no. 3, (2020), pp. 58-63.

3. M. Arulaalan and L. Nithyanandan, "Dual Band Triangular Microstrip Antenna for WLAN/WiMAX Applications", International Journal on Communications Antenna and Propagation, vol.6, no.3, (2016), pp.132-137.

4. A. Kunwar, A. K. Gautam and K. Rambabu, "Design of a Compact U-shaped Slot Triple Band Antenna for WLAN/WiMAX Applications", AEU - International Journal of Electronics and Communications, vol. 71, (2017), pp.82-88.

5. M. Khan and D. Chatterjee, "Characteristic Mode Analysis of a Class of Empirical Design Techniques for Probe-fed, U-slot Microstrip Patch Antennas," IEEE Trans. Antennas. Propaga., vol. 64, no. 7, (2016), pp.2758-2770.

6. F. Yang, X. X. Zhang, X. Ye, and Y. Rahmat-Samii, "Wide-Band E-shaped Patch Antennas for Wireless Communications," IEEE Trans. Antennas Propag., vol. 49, no. 7, (2001), pp. 1094-1100.

7. R. K. Prasad, D. K. Srivastava and J. P. Saini, "Design and Analysis of Gain and Bandwidth Enhanced Triangular Microstrip Patch Antenna", International Journal on Communication Antenna and Propagation (IRECAP), vol. 8, no.1, (2018), pp.1-8.

8. R. Garg, P. Bhartia, I. Bahl, and A. Ittipiboon, "Microstrip Antenna Design Handbook", Artech House, Norwood, MA, USA, (2001).

9. Ravi Kant Prasad, D. K. Srivastava and J. P. Saini, "Step Loaded with Right-angled Bend Microstrip Patch Antenna for 2.42/3.88/5.2 GHz Wireless Application", International Journal of Control Theory and Applications (I J C T A),Vol. No. 9, Issue No.40, ISSN: 0974-5572, pp. 535-543,2016.

10. C. Y. D. Sim, C. C. Chang, and J. S. Row, "Dual-Feed Dual-Polarized Patch Antenna with Low Cross Polarization and High Isolation", IEEE Trans. Antennas Propag., vol. 57, no. 10, (2009), pp. 3321-3324.

11. Ravi Kant Prasad, D. K. Srivastava and J. P. Saini, "Design and Analysis of Gain and Bandwidth Enhanced Triangular Microstrip Patch Antenna", International Journal on Communications Antenna and Propagation (IRECAP), Vol. 8, No 1, pp.1-8, Feb 2018.

12. T. Kueathaweekun, "A Study of Dual/Triple-Band Microstrip-Fed Slot Antenna Design for WLAN/Wi-MAX Communication Systems", International Journal on Communications Antenna and Propagation (IRECAP), vol. 7, no.2, (2017), pp.95-103.

13. Ravi Kant Prasad, D. K. Srivastava and J. P. Saini, "Design of Compact Multiband Rectangular Microstrip Patch Antenna for IEEE 802.11 Standards", Journal of Engineering and Applied Sciences, ISSN: 1816-949X, Vol.13, Issue 7, pp. 1663-1669, 2018.

14. N.N.Trang and C. Fumeaux, "A Frequency and Polarization Reconfigurable Stub Loaded Microstrip Patch Antenna", IEEE transactions on Antennas and Propagation, vol.63, issue. 11, (2015), pp.5235-5240.

\section{AUTHORS PROFILE}

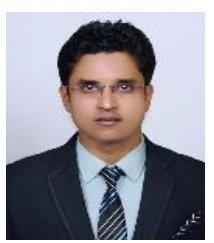

Navneet Singh is a research scholar at Shri Venkateshwara University. He has obtained his B.Tech, M.Tech in Electronics Engineering from different reputed Universities of India. He has been published 4 research articles in different reputed Journals.

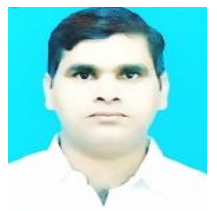

Dr. Dinesh Kuamr Singh is working as Assistant Professor in Department of IT, Dr Shakuntala Misra National Rehabilitation University, Lucknow. He has obtained B.Tech, M.Tech PhD in Computer Science from different reputed universities of India. He has been teaching Object Oriented Programming Language, Network Communication to U.G. and P.G. students for more than 16 years. He has been published 16 research articles in different reputed journals.

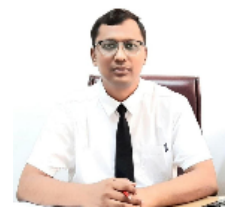

Dr. Amit Jain is currently working as Professor in Shri Venkateshwara University. He has obtained his B.Tech, M.Tech and PhD from different reputed Universities of India. He has been guided many PhD and PG scholars. He has been published more than 36 research articles in different reputed Journals.

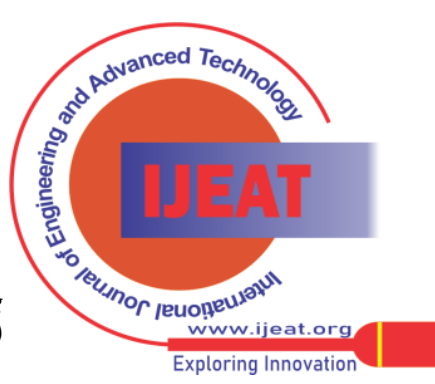

